\title{
Phenotypic and Genotypic Analysis of Antibiogram of Pasteurella multocida Isolated from Pneumonic Sheep Lungs
}

\author{
K. V. Susmitha ${ }^{1^{*}}$, K. Lakshmi Kavitha ${ }^{1}$, M. Srivani ${ }^{1}$ and V. Ramadevi ${ }^{2}$ \\ ${ }^{1}$ Department of Veterinary Microbiology, ${ }^{2}$ Department of Veterinary Pathology Gannavaram, \\ ADDL, Labbipet, Vijayawada, India \\ *Corresponding author
}

\section{A B S T R A C T}

\section{Keywords}

Sheep, Pasteurella multocida,

Phenotypic and Genotypic antibiotic resistance pattern

\section{Article Info}

Accepted:

20 August 2020 Available Online: 10 September 2020
Pasteurella multocida is one of the most frequent causes of respiratory infection in sheep. A total of seven P. multocida were isolated from 195 sheep lung samples. All the isolates were tested to phenotypic antimicrobial resistance pattern with 14 antimicrobial agents. The organisms were found intermediate resistance $57.14 \%$ to Enrofloxacin, $42.85 \%$ to tetracycline, amoxicillin, $28.57 \%$ to colistin and clindamycin. The isolates were resistant to tetracycline $(57.1 \%)$, clindamycin (42.86\%) and chloramphenicol (28.57\%) phenotypically. When the isolates observed for the presence of antibiotic resistance genes it was found $100 \%$ presence of catAl, $71.42 \%$ presence of $s t r B, 57.14 \%$ presence of $\operatorname{str} A, 42.8 \%$ presence of tet $B$ and no amplification of sull, sul2 and tet Agenes. These results indicated the increasing pattern of antibiotic resistance among $P$. multocida isolates.

\section{Introduction}

Pasteurella multocida is a gram negative pathogen responsible for wide range of diseases in domestic animals. Pasteurellosis caused by Pasteurella multocida manifest often as respiratory infection in farmed small ruminants and has major economic and welfare implications worldwide (Odugbo et al., 2006). This organism mainly takes the form of pneumonia and septicaemic pasteurellosis which has been reported in lambs (Watson and Davis, 2002). It has a zoonotic impact in human; it can cause soft tissue infection after animal bites or via inhalation causing respiratory tract infection. Use of antibiotics has widely been reported for the treatment of various diseases caused by $P$. multocida.

However, the prolonged and indiscriminate use of antibiotics has resulted in the development of resistance among various strains of the organism and even multi drug resistant (MDR) forms of $P$. multocida have emerged (Vu-Khac et al., 2020). The present study focused on the phenotypic and genotypic antibiotic resistance pattern of $P$. multocida isolated from sheep lung samples. 
Materials and Methods

\section{Sample Collection}

A total of 195 pneumonic lung samples were collected from sheep slaughter house Gannavaram, Krishna district, Andhra Pradesh.

\section{Bacterial isolation}

From 195 samples, seven P. multocida were isolated as pure culture by following standard bacteriological procedures with specific modifications as described by Sujatha et al., 2018.

\section{Molecular confirmation of the isolates}

Template nucleic acid was isolated using boiling method as described by Sujatha et al 2018. P. multocida specific PCR (PM-PCR) was done using a set of primers as reported by Townsend et al. (1998). A 10ul reaction mixture was used as described by Sujatha $e t$ al., 2018 with PCR conditions initial denaturation $94^{\circ} \mathrm{C}$ for 3 min followed by 30 cycles of denaturation $94^{\circ} \mathrm{C}$ for $30 \mathrm{sec}$, annealing for $57^{\circ} \mathrm{C}$ for $40 \mathrm{sec}$, extension $72^{\circ} \mathrm{C}$ for $60 \mathrm{sec}$ and final extension $72^{\circ} \mathrm{C}$ for 10 min. The amplified gene products were subjected to agarose gel electrophoresis using 1.5\% agarose (Invitrogen, UK) and then visualised by UV gel documentation system ((Bio-Rad).

\section{Phenotypic antibiotic resistance/ sensitivity}

All the isolates were tested for antibiotic resistance/ sensitivity as per Bauer- Kirby et al. (1966) with 14 antibiotics namely Ampicillin-AMP $(10 \mu \mathrm{g})$, Amoxicillin-AMX $(10 \mu \mathrm{g})$, Amoxicillin-Clavulanic acid-AMC $(30 \mu \mathrm{g}), \quad$ Clindamycin- $\quad \mathrm{CD} \quad(2 \mu \mathrm{g})$,

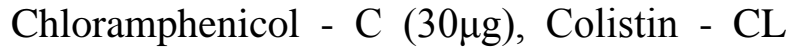
$(10 \mu \mathrm{g})$, Ceftriaxone - CTR $(30 \mu \mathrm{g})$,

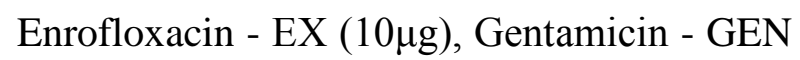
$(10 \mu \mathrm{g})$, Nalidixic acid- NA $(30 \mu \mathrm{g})$, Streptomycin - S $(30 \mu \mathrm{g})$, CotrimoxazoleCOT $(30 \mu \mathrm{g})$, Sulfamethoxazole- $\operatorname{SM}(300 \mu \mathrm{g})$ and Tetracycline - TE $(30 \mu \mathrm{g})$.

Twenty ml of Muller Hinton Agar (MHA) medium was poured in $90 \mathrm{~mm}$ diameter sterile petridishes to a depth of $4 \mathrm{~mm}$ and the plates were incubated at $37^{\circ} \mathrm{C} / 24 \mathrm{~h}$ for sterility check. Test cultures of $P$. multocida enriched in BHI broth (using overnight cultures incubation at $37^{\circ} \mathrm{C}$ for 16 to $18 \mathrm{~h}$.) were used as inoculums. The inoculum was spread to get lawn culture with the help of sterile cotton swab evenly over the entire surface of the MHA plates by swabbing back and forth across the agar. Antibiotic discs were deposited aseptically by using sterile forceps. The plates were incubated at $37^{\circ} \mathrm{C}$ for 16-24 h. The zones of growth inhibition around the antibiotic discs were measured to the nearest millimetre. The zone diameters of each drug were interpreted using the criteria chart provided by CLSI, (2007). Based on the disc diffusion diameters, results were interpreted qualitatively as susceptible, intermediate, and resistant.

\section{Genotypic antibiotic resistance / sensitivity}

Theisolates were tested for presence of antibiotic resistance genes genotypically using sull and sul2 (sulphonamides), catAl (chloramphenicol), strA and $s t r B$ (streptomycins), tet $A$ and $t e t B$ (tetracyclines) primers. The PCR reaction mixture and conditions for each primer has been listed in table 1 and 2, respectively.

\section{Results and Discussion}

Phenotypic antibiogram pattern of $P$. multocida

In the present study all the $7 P$. multocida isolates were tested for their antibiotic 
resistance/ sensitivity pattern by disc diffusion method against commonly used antibiotics. The organisms revealed sensitivity $100 \%$ to gentamicin, cotrimoxazole, ceftriaxone, ampicillin, sulfamethoxazole, streptomycin, amoxicillin-clavulanic acid, nalidixic acid, $71.42 \%$ to chloramphenicol and colistin, $57.1 \%$ to amoxicillin, $42.85 \%$ enrofloxacin and $28.57 \%$ to clindamycin.
The organisms were intermediate resistance $57.14 \%$ to Enrofloxacin, $42.85 \%$ Tetracycline, amoxicillin, $28.57 \%$ to colistin and clindamycin.

The organisms were resistant to tetracycline $(57.1 \%)$, clindamycin $(42.86 \%)$ and chloramphenicol $(28.57 \%)$. The results were presented in Fig. 1 and 2.

Table.1 Primers used for detection of antibiotic resistance genes

\begin{tabular}{|c|c|c|c|c|}
\hline S.no & $\begin{array}{l}\text { Primer } \\
\text { Gene }\end{array}$ & Primer Sequence $\left(5^{1}----3^{1}\right)$ & $\begin{array}{l}\text { Amplicon } \\
\text { size (bp) }\end{array}$ & Reference \\
\hline \multirow[t]{2}{*}{1} & sull $\mathrm{F}$ & GTG ACG GTG TTC GGC ATT CT & 779 & \multirow{4}{*}{$\begin{array}{l}\text { Boerlin et } \\
\text { al. (2005) }\end{array}$} \\
\hline & sull $\mathrm{R}$ & TCC GAG AAG GTG ATT GCG CT & & \\
\hline \multirow[t]{2}{*}{2} & sul2 F & CGG CAT CGT CAA CAT AAC CT & \multirow[b]{2}{*}{721} & \\
\hline & $\operatorname{sul2} \mathrm{R}$ & TGT GCG GAT GAA GTC AGC TC & & \\
\hline \multirow[t]{2}{*}{3} & catAl F & AGTTGCTCAATGTACCTATAACC & \multirow[t]{2}{*}{547} & \multirow{2}{*}{$\begin{array}{l}\text { Sheryl et } \\
\text { al. (2008) }\end{array}$} \\
\hline & catA1 $\mathrm{R}$ & TTGTAATTCATTAAGCATTCTGCC & & \\
\hline \multirow[t]{2}{*}{4} & strA F & CCTGGTGATAACGGCAATTC & \multirow[t]{2}{*}{546} & \multirow{4}{*}{$\begin{array}{l}\text { Boerlin et } \\
\text { al. (2005) }\end{array}$} \\
\hline & $\operatorname{strA} \mathrm{R}$ & CCAATCGCAGATAGAAGGC & & \\
\hline \multirow[t]{2}{*}{5} & $\operatorname{str} B \mathrm{~F}$ & ATCGTCAAGGGATTGAAACC & \multirow[t]{2}{*}{509} & \\
\hline & $\operatorname{str} B \mathrm{R}$ & GGATCGTAGAACATATTGGC & & \\
\hline \multirow[t]{2}{*}{6} & tetA $F$ & GGCGGTCTTCTTCATCATGC & & \multirow{4}{*}{$\begin{array}{l}\text { Boerlin et } \\
\text { al. (2005) }\end{array}$} \\
\hline & tetA $R$ & CGGCAGGCAGAGCAAGTAGA & 500 & \\
\hline \multirow[t]{2}{*}{7} & tetB $F$ & CATTAATAGGCGCATCGCTG & \multirow[b]{2}{*}{540} & \\
\hline & tetB $R$ & TGAAGGTCATCGATAGCAGG & & \\
\hline
\end{tabular}

Table.2 Standardization of PCR protocols for the detection of Antibiotic resistance genes for $P$. multocida and M. haemolytica

\begin{tabular}{|c|c|c|c|c|c|c|c|}
\hline $\begin{array}{c}\text { S. } \\
\text { No }\end{array}$ & Gene & $\begin{array}{c}\text { Initial } \\
\text { Denaturation } \\
\left({ }^{\circ} \mathbf{C} / \mathbf{m i n}\right)\end{array}$ & $\begin{array}{c}\text { Denaturation } \\
\left({ }^{\circ} \mathbf{C} / \mathbf{s e c}\right)\end{array}$ & $\begin{array}{c}\text { Annealing } \\
\left({ }^{\circ} \mathbf{C} / \mathbf{s e c}\right)\end{array}$ & $\begin{array}{c}\text { Extension } \\
\left({ }^{\circ} \mathbf{C} / \mathbf{s e c}\right)\end{array}$ & $\begin{array}{c}\text { Final } \\
\text { Extension } \\
\left({ }^{\circ} \mathbf{C} / \mathbf{m i n}\right)\end{array}$ & $\begin{array}{c}\text { No of } \\
\text { cycles }\end{array}$ \\
\hline $\mathbf{1}$ & sull & $95 / 4 \mathrm{~min}$ & $95 / 60 \mathrm{sec}$ & $68 / 60 \mathrm{sec}$ & $72 / 60 \mathrm{sec}$ & $72 / 7 \mathrm{~min}$ & 35 \\
\hline $\mathbf{2}$ & sul2 & $95 / 4 \mathrm{~min}$ & $95 / 60 \mathrm{sec}$ & $66 / 60 \mathrm{sec}$ & $72 / 60 \mathrm{sec}$ & $72 / 7 \mathrm{~min}$ & 35 \\
\hline $\mathbf{3}$ & catAl & $94 / 4 \mathrm{~min}$ & $94 / 30 \mathrm{sec}$ & $55 / 40 \mathrm{sec}$ & $72 / 60 \mathrm{sec}$ & $72 / 10 \mathrm{~min}$ & 30 \\
\hline $\mathbf{4}$ & strA & $95 / 4 \mathrm{~min}$ & $95 / 60 \mathrm{sec}$ & $55 / 60 \mathrm{sec}$ & $72 / 60 \mathrm{sec}$ & $72 / 10 \mathrm{~min}$ & 35 \\
\hline $\mathbf{5}$ & strB & $95 / 4 \mathrm{~min}$ & $95 / 60 \mathrm{sec}$ & $55 / 60 \mathrm{sec}$ & $72 / 60 \mathrm{sec}$ & $72 / 10 \mathrm{~min}$ & 35 \\
\hline $\mathbf{6}$ & tetA & $95 / 5 \mathrm{~min}$ & $94 / 30 \mathrm{sec}$ & $48 / 30 \mathrm{sec}$ & $72 / 1 \mathrm{~min}$ & $72 / 10 \mathrm{~min}$ & 30 \\
\hline $\mathbf{7}$ & tetB & $94 / 5 \mathrm{~min}$ & $94 / 30 \mathrm{sec}$ & $55 / 30 \mathrm{sec}$ & $72 / 1 \mathrm{~min}$ & $72 / 10 \mathrm{~min}$ & 30 \\
\hline
\end{tabular}


Table.3 Distribution of antibiotic resistance genes in $P$. multocida isolates by PCR

\begin{tabular}{|c|c|c|c|c|c|c|c|}
\hline Sample no. & sull & sul2 & catAI & strA & strB & tetA & tetB \\
\hline $7-1$ & - & - & + & + & + & - & - \\
\hline $18-1$ & - & - & + & - & + & - & + \\
\hline $20-1$ & - & - & + & + & - & - & - \\
\hline $23-4$ & - & - & + & + & - & - & + \\
\hline $23-5$ & - & - & + & + & + & - & - \\
\hline $23-6$ & - & - & + & - & + & - & - \\
\hline $23-7$ & - & - & + & - & - & - & + \\
\hline
\end{tabular}

Table.4 Comparison of phenotypic and genotypic pattern of antibiotic resistance genes in $P$. multocida isolates

\begin{tabular}{|c|c|c|c|c|c|c|c|c|c|c|c|}
\hline Sample no. & SM & sull & sul2 & C & catAl & S & strA & strB & TE & tetA & tetB \\
\hline $\mathbf{7 - 1}$ & S & - & - & S & + & S & + & + & I & - & - \\
\hline $\mathbf{1 8 - 1}$ & S & - & - & R & + & S & - & + & R & - & + \\
\hline $\mathbf{2 0 - 1}$ & S & - & - & S & + & S & + & - & R & - & - \\
\hline $23-4$ & S & - & - & S & + & S & + & - & I & - & + \\
\hline $23-5$ & S & - & - & S & + & S & + & + & R & - & - \\
\hline $23-6$ & S & - & - & R & + & S & - & + & R & - & - \\
\hline $23-7$ & S & - & - & S & + & S & - & - & I & - & + \\
\hline
\end{tabular}

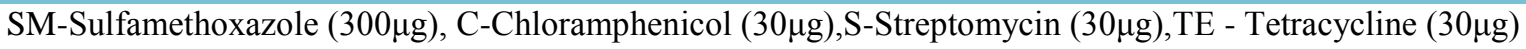

Fig.1 Phenotypic antibiotic sensitivity / resistance pattern of $P$. multocida

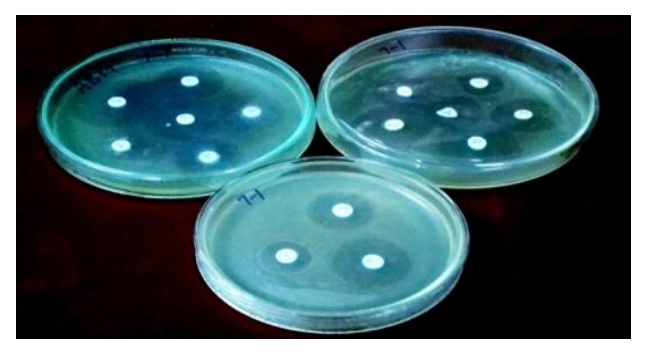

Fig.2 Phenotypic antibiotic sensitivity/resistance pattern of $P$. multocida

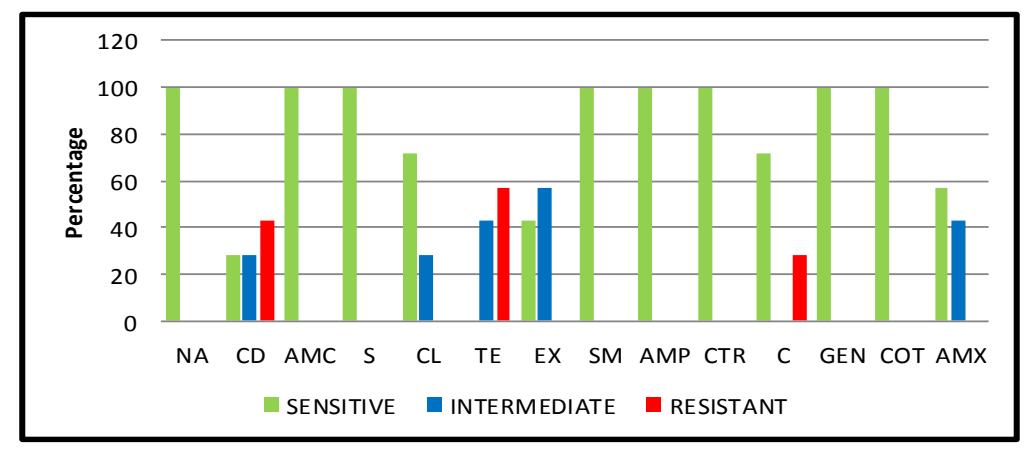


Fig.3 PCR amplification of catAl gene

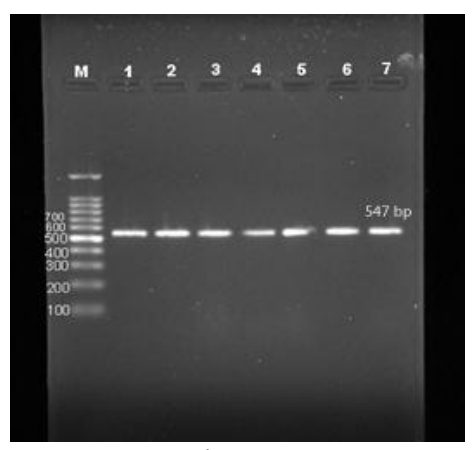

Lane M- Marker

Lane 1, 2, 3, 4, 5, 6, 7- positive

Fig.4 PCR amplification of strA gene

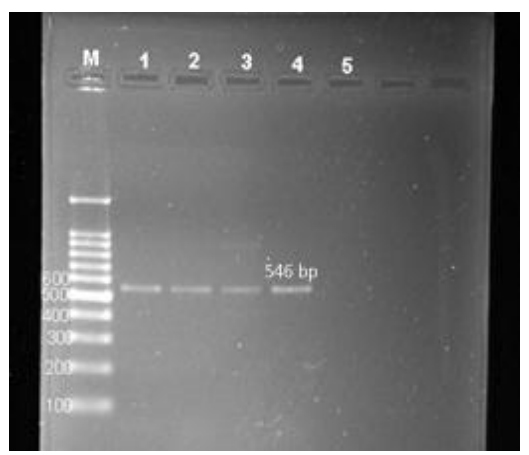

Lane M- Marker

Lane 1, 2, 3, 4- positive samples

Lane 5- negative control

Fig.5 PCR amplification of $\operatorname{str} B$ gene

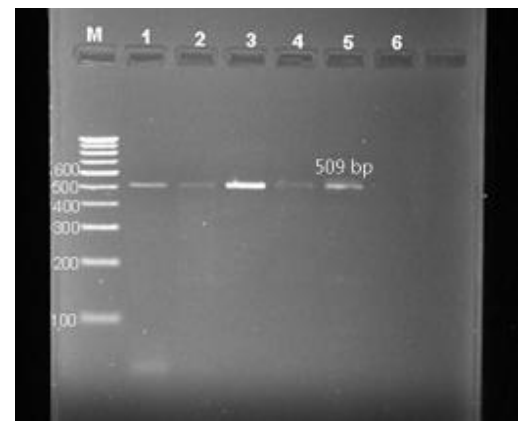

Lane M- Marker

Genotypic antibiotic resistance pattern of P. multocida

The genotypic antibiotic resistance gene distribution of $P$. multocida was checked with the help of PCR. Primers for sull, sul2,
catAl, strA, strB, tetA and tetB were used which resulted in amplified band width of 779 bp, 721 bp, 547 bp, 546 bp, 509 bp and 540bp, respectively. The positive amplification was shown in Fig. 3, 4 and 5. 
Of the 7 antimicrobial genes examined, no isolate was found to be positive for sull and $s u l 2$, all the isolates were positive for catAl (100\%), 4 were found to be positive for strA $(57.14 \%)$ and 5 for $\operatorname{str} B(71.42 \%)$, tetA was negative in all the isolates and tet $B$ was found in 3 isolates (42.85\%). Two isolates (7-1 and 23-4) possessed 3 genes catA1, strA and strB. Distribution of the antibiotic resistance genes and their comparison with phenotypic resistance were shown in Table 3 and 4.

The isolation and identification of Pasteurella multocida from primary cultures was done by observing standard cultural and biochemical properties of the $P$. multocida. The conventional procedures were supported by observing an amplified product of $460 \mathrm{bp}$ in PCR that confirmed the occurrence of $P$. multocida in the isolated sample (Sujatha et al., 2018; Sarangi et al., 2014; Prabhakar et al., 2012; Ewers et al., 2006). Out of 195 samples 7pure cultures were obtained and were used for studying antibiogram pattern.

The antibiogram pattern of the pathogen is an important aid for veterinarian to select most effective therapeutic agents. Hence, the pure colonies of $P$. multocida were subjected to antibiotic sensitivity test. Among the 14 antibiotics tested,the organisms revealed sensitive $100 \%$ to gentamicin, cotrimoxazole, ceftriaxone, ampicillin, sulfamethoxazole, streptomycin, amoxicillin-clavulanic acid, nalidixic acid, $71.42 \%$ to chloramphenicol and colistin, $57.1 \%$ to amoxicillin, $42.85 \%$ enrofloxacin and $28.57 \%$ to clindamycin. Though the organisms sensitive to some antibiotics but they showed intermediate resistance $57.14 \%$ to Enrofloxacin, $42.85 \%$ Tetracycline, amoxicillin, $28.57 \%$ to colistin and clindamycin and resistance $57.14 \%$ to tetracycline, $42.86 \%$ to clindamycin, $28.57 \%$ to chloramphenicol. The multidrug resistance of $P$. multocida of sheep was also supported by Emikpe et al., (2014), Marru et al., (2013) and Rajkhowa et al., (2012). In the study, sheep isolates revealed $100 \%$ sensitive to sulfamethoxazole which is a positive indication. It was also evident that sulfonamides are the drug of choice in the treatment of pasteurellosis (Radostits et al., 2006). However the use of sulfonamides in the treatment of $P$. multocida was override by the use of fluoroquinolone and other higher antibiotics in day to day practice. In present study it was observed that the isolates showed increased resistance to Enrofloxacin. Moreover, the organisms also exhibited intermediate resistance pattern to colistin at $28.57 \%$ which is an alarming sign indicating that organisms are acquiring higher antibiotic resistance as colistin is being treated as the last resort antibiotic for Gram negative organisms (Cheng et al., 2015). These results necessitate the prudent use of antibiotics during therapy.

The genotypic antibiogram of $P$. multocida resulted no amplification for sulland sul2genes, $100 \%$ amplification for catAl, $71.42 \%$ for $s t r B, 57.14 \%$ for $s t r A, 42.85 \%$ to tet $B$ genes and no amplification for tetA gene. Among these isolates, some possesses three genes (catA1, strA, strB for 7-1 isolate and catAl, strB, tetB for 18-1 isolate). When it was compared with previous study on Pasteurella multocida in bovines (Sujatha, 2016) which showed resistance to suplphonamides, sheep isolates resulted sensitivity to sulphonamides and absence of genes sul1, sul2. None of the bovine isolates harbored catAl, strA and strB (Sujatha, 2016) but ovine isolates harbored the genes related to chloramphenicol (catAl), streptomycin (strA, strB) and tetracycline (tet $A, \operatorname{tet} B)$ which is due to the variation in the use of antibiotics in the treatment of pneumonia in bovines and ovines. Furthermore the comparison of phenotypic and genotypic pattern of antibiotic resistance, the correlation was observed with sulphonamides. But there was less correlation 
between presence of gene and phenotypic antibiogram of other antibiotics. Such type of discrepancies was also observed in $P$. multocida and other gram negative bacteria (Vu-Khacet al., 2020, Srivani. 2017, Sujatha. 2016, Davis et al., 2011).

The present study provided useful information on the distribution of antibiotic resistance in $P$. multocida. It was also recommended that not only the treatment of the disease with antibiotics but also improvement of managemental practices by providing optimal sanitation, air quality in housing, minimizing transportation stress, providing good quality hay and water along with proper vaccination is necessary to reduce the occurrence of disease (Marru et al., 2013).

\section{Acknowledgement}

The authors are grateful to the Sri Venkateswara Veterinary University, Tirupati for providing financial support and necessary facilities for post graduation study.

\section{References}

Bauer, A. W., Kirby, W. M., Sherris, J. C., and Turck, M. 1966. Antibiotic susceptibility testing by a standardized single disk method. J. Clin. Pathol.45: 493-496.

Boerlin, P., Travis, R., Gyles, C. L., Smith, R. R., Janecko, N., Lim, H., Nicholson, V., McEwen, S. A., Robert, F. and Archambault, M. 2005. Antimicrobial Resistance and Virulence Genes of Escherichia coli Isolates from Swine in Ontario. Appl. Environ. Microbiol. 71: 6753-6761

Cheng, Y.H., Cin, T.L., Pan, Y.J., Wang, U.D., Lin, Y.T. and Wang, J.T. 2015. Colistin resistance mechanisms in Klebsiella pneumoniae strains from Taiwan. Antimicrob. Agents. Chemother.
59:2909-2913.

Clinical and Laboratory Standards Institute (2007) Performance Standards for Antimicrobial susceptibility testing; Fifteenth Informational Supplement. CLSI document M100- S15. CLSI, Wayne, PA.

Davis, M. A., Besser, T. E., Orfe, H. L., Baker, K. N. K., Lanier, S. A., Broschat, L. S., New, D. and Call, R. D. 2011. Genotypic - phenotypic discrepancies between antibiotic resistance characteristics of Escherichia coli isolates from calves in management settings with high and low antibiotic use. Appl. Environ. Microbiol.77:3293-3299.

Emikpe, B. O., Tijani, L. A., Karim, M. O., Omoniyi, A. S. and Akanbi, I. M. 2014. Isolation and antibiogram of pneumonic pasteurellosis causing microbes from nasopharynx of transport stressed Nigerian goats. Afr.J. Microbiol. Res. 8:441-445.

Ewers, C., Lubke Becker, A., Becker, A., Bethe, A., Kieblings., Filter, M. and Wiefer, H. 2006. Virulence genotype of Pasteurella multocida strains isolated from different hosts with various disease status. Vet. Microbiol. 114: 304-317.

Marru, H. D., Anijajo, T. T. and Hassen, A. A. 2013. A study on Ovine pneumonic pasteurellosis: Isolation and Identification of Pasteurella and their antibiogram susceptibility pattern in Haramaya District, Eastern Hararghe, Ethiopia. BMC Vet. Res.9:1-8.

Odugbo, M. O., Odama, L. E., Umoh, J. U. and Lamorde, A. G. 2006.Pasteurella multocida pneumonic infection in sheep: Prevalence, clinical and pathological studies. Small. Ruminant. Res. 66:273277.

Prabhakar, P., Thangavelu, A., Kirubaharan, J. J. and Chandran, N. D. J. 2012. Isolation and characterisation of $P$. multocida isolates from small ruminants 
and avian origin. Tamilnadu. J. Vet. Ani. Sci. 8: 131-137.

Radostits, O. M., Gay, C., Blood, D. C. and Hinchcliff, K. W. 2006. A textbook of the diseases of cattle, sheep, pigs, goats, and horses. 10th ed., Saunders, Philadelphia, London.

Rajkhowa, S., Shakuntala, I., Pegu, S. R., Das, R. K. and Das, A. 2012. Detection of Pasteurella multocida isolates from local pigs of India by polymerase chain reaction and their antibiogram. Trop. Anim. Health. Pro. 44:1497-1503.

Sarangi, L. N., Priyadarshini, A., Santhosh Kumar., Prasad, T., Santhosh Kumar, G., Nagaleekar, V. K. and Vijendra Pal Singh. 2014. Virulence genotyping of Pasteurella multocida isolated from multiple hosts from India. Sci. World. J. 1-10.

Sheryl, P. G., Cheryl, L. W., Josee, H. and Boerlin, P. 2008. Associations between Antimicrobial Resistance Genes in Faecal Generic Escherichia coli isolates from Cow-Calf Herds in Western Canada. Appl. Environ. Microbiol. 74: 3658-3666.

Srivani, M. 2017. Epidemiology, molecular characterization and antimicrobial resistance of Escherichia coli isolates from diarrhoeic calves. Ph.D thesis, P.V. Narasimharao Telangana Veterinary
University, Hyderabad.

Sujatha, N. 2016. Molecular characterization of Pasteurella multocida isolates of buffaloes. M.V.Sc thesis, Sri Venkateswara Veterinary University, Tirupati.

Sujatha, N., Kavitha, K. L., Subramanyam, K. V., Rao, T. S. and Srivani, M. 2018. Isolation and molecular characterization of Pasteurella multocida isolates of buffaloes. Indian. J. Comp. Microbiol. Immunol. Infect. Dis. 39: 1-6.

Townsend, K. M., Frost, A. J., Lee, C. W., Papadimitriou, J. M. and Dawkins, J. S. 1998. Development of PCR assays for Species and Type Specific Identification of Pasteurella multocida isolates. J. Clin. Microbiol.36: 1096-1100.

Vu-Khac, H., Trinh, T.T.H., Nguyen, T.T.G., Nguyen, X.T., Nguyen, T.T. 2020. Prevalence of virulence factor, antibiotic resistance, and serotype genes of Pasteurella multocida strains isolated from pigs in Vietnam. Vet. World. May; 13(5): 896-904. doi: 10.14202/vetworld.2020.896-904. Epub 2020 May 15. PMID: 32636585; PMCID: PMC7311876.

Watson, P. J. and Davies, R. L. 2002. Outbreak of Pasteurellamultocida septicaemia in neonatal lambs. Vet. Rec. 151: 420-422.

\section{How to cite this article:}

Susmitha, K. V., K. Lakshmi Kavitha, M. Srivani and Ramadevi, V. 2020. Phenotypic and Genotypic Analysis of Antibiogram of Pasteurella multocida Isolated from Pneumonic Sheep Lungs. Int.J.Curr.Microbiol.App.Sci. 9(09): 2913-2920.

doi: https://doi.org/10.20546/ijcmas.2020.909.358 